University of Wollongong

Research Online

Faculty of Social Sciences - Papers (Archive) Faculty of Arts, Social Sciences \& Humanities

2013

AsthmaWise - a field of dreams? The results of an online education program targeting older adults with asthma

Pippa Burns

University of Wollongong, prhb62@uowmail.edu.au

Sandra C. Jones

University of Wollongong, sandraj@uow.edu.au

Donald C. Iverson

University of Wollongong, iverson@uow.edu.au

Peter Caputi

University of Wollongong, pcaputi@uow.edu.au

Follow this and additional works at: https://ro.uow.edu.au/sspapers

Part of the Education Commons, and the Social and Behavioral Sciences Commons

Research Online is the open access institutional repository for the University of Wollongong. For further information contact the UOW Library: research-pubs@uow.edu.au 


\title{
AsthmaWise - a field of dreams? The results of an online education program targeting older adults with asthma
}

\begin{abstract}
Objectives: The aim of this study was to establish the feasibility and acceptability of an online asthma self-management program developed for older Australians with asthma. Methods: AsthmaWise, an internet education self-management program, was piloted for a 3-month period at the beginning of 2012. Participants were recruited using both online and offline strategies and were required to complete surveys, both pre- and post-intervention, in a repeated measures design. Results: Matched data were collected from 51 participants; the results showed AsthmaWise to be a feasible and acceptable method of delivering asthma education to the target population. Self-reported measures showed an increase in participants' asthma knowledge, asthma control and quality of life. Results from the Perceived Health Web Site Usability Questionnaire (PHWSUQ) showed improvements between usability testing and implementation. Conclusion: The need for asthma self-management education will continue to increase as the population ages and a greater number of older adults are living with asthma. This small pilot study indicates that an online asthma self-management education program can result in improved outcome measures in a target group not normally considered technologically literate.
\end{abstract}

\section{Keywords}

results, targeting, dreams, field, asthmawise, asthma, program, older, adults, education, online

\section{Disciplines}

Education | Social and Behavioral Sciences

\section{Publication Details}

Burns, P., Jones, S. C., Iverson, D. \& Caputi, P. (2013). AsthmaWise - a field of dreams? The results of an online education program targeting older adults with asthma. Journal of Asthma, 50 (7), 737-744. 


\section{Abstract}

\section{Objectives}

The aim of this study was to establish the feasibility and acceptability of an online asthma self-management program developed for older Australians with asthma.

\section{Methods}

AsthmaWise, an internet education self-management program, was piloted for a three month period at the beginning of 2012. Participants were recruited using both online and offline strategies, and were required to complete surveys, both pre and post intervention, in a repeated measures design.

\section{Results}

Matched data was collected from 51 participants; the results showed AsthmaWise to be a feasible and acceptable method of delivering asthma education to the target population. Self-reported measures showed an increase in participants' asthma knowledge, asthma control and quality of life. Results from the Perceived Health Web Site Usability Questionnaire (PHWSUQ) showed improvements between usability testing and implementation. 


\section{Conclusion}

The need for asthma self-management education will continue to increase as the population ages and a greater number of older adults are living with asthma. This small pilot study indicates that an online asthma self-management education program can result in improved outcome measures in a target group not normally considered technologically literate. 


\section{Introduction:}

Approximately one in ten people have an asthma diagnosis, which equates to over two million people in Australia alone $(1,2)$. The associated mortality and morbidity creates a large burden on the Australian health system (Australian Institute of Health and Welfare, 2010) which currently lies mostly with older adults (3,4). Significantly, asthma is associated with poorer quality of life, with sufferers reporting a higher proportion of days with reduced activity than people without asthma (Australian Centre for Asthma Monitoring, 2008). While there is currently no cure for asthma, effective self-management has been shown to lead to: fewer attacks, effective symptom control, and improved quality of life (5-9). Current Australian asthma self-management guidelines incorporate: self-monitoring, regular medication review, and the use of a written asthma action plan (10). While the management of asthma in the elderly does not differ from that in younger patients, it can be complicated by the decline in physical and cognitive functioning often seen with aging. Further, asthma is more likely to occur along with other co-morbidities in older adults, altering the presentation of the asthma and complicating disease management. It has been recognised that asthma management amongst the elderly is likely to improve if educational interventions are tailored to their specific needs $(5,11)$. However, there is currently a lack of asthma management support targeted specifically at this age group.

Asthma education has the potential to be delivered online; however, to date, most of these self-management tools have included the monitoring of symptoms and the involvement of healthcare professionals such as the patient's physician or an asthma nurse (12-20). Some 
of these interventions have shown improvements in asthma control $(13,14,20)$ and lung function (20), but little change in quality of life (20) or asthma exacerbations (20).

Online patient education has a wider reach than traditional face-to-face methods. Its flexible delivery allows recipients to view materials at convenient times and locations, reducing the burden of travel incurred when attending traditional face-to-face patient education. Most of the provider costs are incurred during development, while additions and corrections are quick and relatively inexpensive to undertake and deploy. Further, it is recognised that information technology can increase both understanding of, and participation in, health care which, in turn, can increase empowerment (21) and provide users with a more comprehensive understanding of their asthma than standard asthma education (22). Trials of online asthma education have not, as far as can be discerned, previously focused solely on older adults.

This paper discusses the piloting of AsthmaWise, an online education site for older adults with asthma. AsthmaWise was created by a University research group in partnership with Asthma Foundation New South Wales (AFNSW), following two years of formative research with the target population. AsthmaWise contained six education modules, which were written in English and could be completed in any order. The module topics were designed to take a maximum of 15 minutes each to complete. The content was guided by Asthma Foundation NSW and was in accordance with the Australian National Asthma Treatment Guidelines (10). The modules were also informed by the Theory of Planned Behaviour (23) 
as it is known that programs based on behavioural theories are more likely to produce positive outcomes $(22,24-26)$. The levels of interaction and tailoring proposed for AsthmaWise were guided by previous work (25,27-32). Website design guidelines were used to optimise accessibility and usability for the target audience (33-35).

The program aimed to increase users' understanding of asthma and provide them with the tools needed to adequately self-manage their disease through the delivery of six modules. The modules were: (1) Asthma: what is it, what causes it and who gets it?; (2) Asthma treatments: medications and complementary therapies; (3) Asthma triggers: what makes your asthma worse?; (4) Asthma control check: are you in control?; (5) Asthma and life: exercise, gardens, food, smoking and products; and (6) Managing an asthma attack: what to do. AsthmaWise was password protected and could only be accessed after the user had completed registration.

This study aimed to establish the feasibility and acceptability of an online asthma selfmanagement program amongst older Australians with asthma. Changes in asthma knowledge, asthma control, asthma self-management efficacy and asthma quality of life were also measured. 


\section{Methods:}

\section{Formative Research}

AsthmaWise was developed based on findings from two years of formative research. First, a paper-based survey was sent to 9,000 randomly selected older adults in New South Wales, Australia (response rate $=46.8 \%, n=4,066$ ) to explore the health beliefs, attitudes and behaviours of older Australians towards asthma. This information was used to inform the content of AsthmaWise. Second, four focus groups were conducted to explore the type of interactivity older adults felt would be beneficial on an asthma education site, with particular reference to blogs and forums $(n=26)$. Based on these results AsthmaWise was subsequently developed by AFNSW using Moodle (Moodle, Perth, Australia), an open source learning management system that enables educators to create dynamic web sites. Usability testing was undertaken on the AsthmaWise prototype with older adults $(n=13)$ who completed tasks on three sections of AsthmaWise. A cognitive walk through by an independent researcher and readability testing of the pages were also conducted (36). AsthmaWise was subsequently refined and piloted for a three month period at the beginning of 2012. The revised Flesch-Kincaid Grade Level for the modules tested was assessed at 9.74 \pm 0.76 ; while the Flesch Reading Ease Score was 59.81 \pm 2.43 . These were slightly outside the target ranges of eight or below for the Flesch-Kincaid Grade Level and 60 to 70 for the Flesch Reading Ease (36). Approval for this study was granted through the University's Human Research Ethics Committee. 


\section{Recruitment and Registration}

A mixture of online and offline methods were utilised to recruit adults, aged 55 years and over, with asthma. Offline promotional flyers were distributed to dispensing pharmacies, and participants from previous stages of the research were invited to take part in the pilot. Online, two Facebook adverts targeting older adults in New South Wales were deployed; in addition two targeted emails from First Direct, a subsidiary of Australia Post, were sent to email addresses of older adults in NSW with asthma. AsthmaWise was also publicised by the following organisations: Pharmacy Guild NSW; General Practice NSW; Council on the Ageing NSW (COTA); Country Women's Association of NSW (CWA); Seniors Clubs NSW; and the Illawarra Shoalhaven Medicare Local.

People interested in taking part in the piloting of AsthmaWise were asked to register their interest online. The registration process contained seven items; the first five items screened for eligibility (age, asthma diagnosed by a health professional, current asthma, postcode and suburb); participants were required to be aged 55 years or over and have current asthma. Initially geographic location was restricted to two regions of New South Wales, but lower than expected recruitment resulted in the intervention being opened up to residents throughout New South Wales. The final two items asked for contact information (name and email address). Due to difficulties recruiting participants, recruitment was left open during the pilot period. 


\section{Pre-test survey}

On the day AsthmaWise went live, registered participants were emailed a link to the pretest questions, via Informz (email marketing software). These questions had to be completed before people were able to access AsthmaWise. The pre-test survey contained 10 groups of items including information on participants' demographics, internet use and health.

A modified version of the consumer asthma knowledge questionnaire (37) was incorporated. Four questions were excluded on the advice of AFNSW who perceived them to be not consistent with current asthma management guidelines; and two items were omitted. The other six questions were scored 'true' or 'false'. A high mean score indicated better asthma knowledge. Psychometrics for this tool have been previously report (37). Cronbach's Alpha for the scale at pre-test was .54 . While this value indicates low internal consistency, we continued with this tool for the purpose of this research.

Asthma control was measured using the RCP3 tool (38). The RCP3 consists of three questions, which are answered either 'no' (score $=$ zero) or 'yes' (score $=1)$. A total RCP3 score of zero indicates well controlled asthma; a score of one indicates medium morbidity, while a score of two or three indicates high morbidity. A low mean value indicated good asthma control. The RCP3 has been previously shown to reliably measure asthma control (39). Cronbach's Alpha for the scale at pre-test was .72 indicating acceptable internal consistency. The RCP3 was chosen as the Asthma Control Questionnaire was unavailable for 
computer delivery (40) and matching data from the Asthma Control Test to participants' other information would have proved problematic (41).

Asthma quality of life was measured using statements developed to capture the ways in which asthma and its treatment may affect people (42). Participants were asked to choose one of the five response options for each statement: 'not at all', 'mildly', moderately', 'severely' and 'very severely'. A low mean value indicates better asthma related quality of life. Psychometrics for this tool have been previously report $(42,43)$. Cronbach's Alpha for the scale at pre-test was .97 signifying excellent internal consistency.

Asthma self management efficacy was measured using the Partners in Health Scale (44). The scale comprised of 11 questions which were amended to make them specific to asthma. Questions were scored on a nine-point scale, $0=$ very good, $4=$ satisfactory and $8=$ very poor. As such, a low mean value indicated high self-management efficacy. the Partners in Health Scale has been shown to be a valid and reliable measure of chronic condition selfmanagement (44). Cronbach's Alpha for the scale at pre-test was .92 representative excellent internal consistency.

\section{Post-test survey}

AsthmaWise could be accessed from February to April 2012. Emails reminding participants of AsthmaWise were sent out mid-way through the intervention. At the end of the 
intervention an email was sent to participants, via SurveyMonkey, which provided a direct link to the post-test evaluation questions. The post-test survey contained 77 items, including those that were administered in the pre-test, thus allowing matching to pre-test data. A modified version of the PHWSUQ for Older Adults (45) was used to assess participants' overall opinion of AsthmaWise, with 10 questions across three domains: satisfaction; easeof-use; and usefulness. Participants were asked to answer each question using a seven-point likert scale $(1=$ very unsatisfied to $7=$ very satisfied $)$. The usability and reliability of this tool have been reported elsewhere (45). Cronbach's Alpha for the scale at post-test was .93 indicating excellent internal consistency. Health literacy was measured using the screening question "how confident are you at filling out forms by yourself", which has been shown to be useful for detecting people with inadequate health literacy (46).

Two participants were not sent the post-test survey as they had previously indicated they did not want to be contacted by SurveyMonkey. Another three participants contacted the researchers and asked to be excluded as they felt that they had not spent enough time on SurveyMonkey to complete the evaluation. A further person was excluded due to issues accessing the site, leaving a sample of 100 people.

Participants' scores for asthma knowledge, asthma control, asthma self-management efficacy, and asthma quality of life including the four asthma quality of life sub-scales (breathlessness, mood, social and concerns) were summed pre and post intervention. Paired t-tests were run and Pearson's correlation coefficient $(r)$ was calculated as a measure of effect size. 


\section{Web usage data}

Throughout the pilot, web-log data was collected using Google Analytics. This included information on the number of unique site visits; visit duration; and the operating systems and browsers used by participants.

\section{Non-responders}

A reminder email was sent to both non-responders and participants who had not fully completed the post-intervention survey a week after the first email was sent. A second email was sent to non-responders approximately two months later asking them to provide information on six items (age; age at diagnosis; seriousness of asthma; and the three RCP3 questions), allowing a comparison of responders to non-responders. An independent t-test was run to compare responders' and non-responders' age. Age at diagnosis, asthma control and perceived seriousness of asthma were explored using $\chi^{2}$ tests.

\section{The Internet Self-Management Reporting Uniform Framework (iSMURF)}

The Internet Self-Management Reporting Uniform Framework (iSMURF) was used to capture intervention detail under six domains: website design, support, study design, website use, user characteristics and reporting outcomes (47). iSMURF has been proposed as a minimum reporting set, which can facilitate easy comparison of internet selfmanagement interventions target chronic diseases. 


\section{Results:}

One hundred and six people registered and completed the pre-test survey for AsthmaWise; matched pre and post test data was collected from 51 of these participants. Participant demographics are given in Table 1. Most participants reported good health $(70.6 \%$ had good, very good or excellent health status) and had been diagnosed with asthma as an adult but more than five years ago (56.9\%). At baseline, $90.2 \%(n=46)$ had uncontrolled asthma, based on their answers to the RCP3 questions and $17.6 \%(n=9)$ had visited the Emergency Department in the last 12 months because of their asthma. The most frequently reported co-morbidities were arthritis and bronchitis, with $58.8 \%$ of the sample reporting each condition. Most participants reported being long-term internet users (62.7\% had been online for more than five years), with high comfort levels (74.5\% reported being very comfortable online), and high usage rates ( $86.3 \%$ spent more than 10 hours online each week).

$<<$ TABLE 1 >>

\section{Acceptability of AsthmaWise}

The total mean-converted score for the PHWSUQ was 75\%, which was significantly better than the score obtained during usability testing (Table 2). The ranking of the individual domains remained consistent with those obtained during usability testing, with satisfaction scoring highest (81\%) and usefulness scoring lowest (73\%). 
$<<$ TABLE 2>>

Most participants (68.6\%) had decided to visit AsthmaWise to learn more about how to manage their asthma, the majority found AsthmaWise useful (94.1\%).

"I had forgotten some of the detail of some of the things my doctor told me when I was first diagnosed. It was good to be able to refresh and update my knowledge." Female, aged 71 years.

"It was a good check on what I am currently doing." Male, aged 67 years.

Tracking of the site by Google Analytics showed that during the pilot period there were 10,265 page views by 633 unique visitors, which included the 106 registered users. It is likely that some of these visitors found AsthmaWise through Google or other search methods and so did not register to take part in the pilot. The majority of visitors were from Australia (97.67\%), with most residing in Sydney (67.7\%). The average visitor viewed 10.89 pages and stayed on the site for 8.31 mins.

All further results discussed refer to the 51 participants with matched data. Most participants accessed AsthmaWise from home (94.1\%) and found it to be an acceptable 
length (74.5\%). Participants reported that the content was very easy or extremely easy to understand (80.3\%) and that they were very or extremely confident that the content presented was accurate (84.3\%). Most participants reported knowing more about how to manage their asthma after visiting AsthmaWise (78.4\%); with almost half reporting that they had experienced an improvement in their asthma symptoms (49.0\%). Over one-third had made changes to their asthma management as a result of AsthmaWise (36\%), and a further $14 \%$ planned to make changes to their asthma management in the future. Reported changes included: monitoring their asthma symptoms (20\%); making sure that they took their medication regularly (16\%); visiting their General Practitioner (GP) for an asthma review (12\%); and requesting an action plan from their GP (4\%). The barriers most frequently reported, which hindered participants from making changes to their asthma management, were remembering to: monitor their asthma symptoms (28\%) and take their asthma medication (16\%). Over one quarter of participants reported having insufficient time to visit AsthmaWise as frequently as they would have liked (26\%). However, almost all participants said they would recommend AsthmaWise to others with asthma (94\%).

"Especially for those newly diagnosed like late age patients." Male, aged 68 years. "It would be of assistance to long time sufferers who have not consulted a GP for a long time in relation to asthma." Male, aged 67 years. 


\section{Self-reported changes in asthma related health}

Asthma knowledge, asthma control and asthma quality of life were all seen to significantly improve after using AsthmaWise (Table 3). Scores for the three subscales, breathlessness, mood and social also showed significant improvements, while changes in the concerns subscale were not significant (Table 3). The results indicate that participants' asthma selfmanagement efficacy decreased after exposure to the intervention (Table 3).

$<<$ TABLE 3>>

\section{Comparison of post-test non-responders to responders}

Just over one quarter of the 49 participants who did not complete the post-intervention survey responded to the emailed follow-up questions (26.5\%). There was no significant difference in the age, age at diagnosis or asthma control between the responders and nonresponders. However, non-responders were significantly more likely to perceive asthma as not serious when compared to responders $\left[\chi^{2}(1, N=71)=134.12, p=.000\right]$.

\section{The Internet Self-Management Reporting Uniform Framework (iSMURF)}

Data has been provided under all six iSMURF domains (Table 1) as the publication of this information adds to the body of knowledge regarding the effectiveness of online self- 
management education for chronic diseases, by providing detail not just about the users but also in-depth information about the intervention design.

\section{Discussion:}

AsthmaWise was an online asthma self-management education program, which allowed participants to learn more about managing their asthma. Although AsthmaWise targeted older adults aged 55 years and over, the mean age of participants was fairly young (62.5 years). While this was somewhat influenced by the inclusion of five participants aged between 50 and 55 years which occurred due to a technical error, which should have prevented people under the age of 55 from progressing past the registration phase. These participants were included in the analyses due to the relatively small number of total participants and because it may suggest, that such interventions have significant appeal to the young-old. Like other internet delivered education programs, usage of AsthmaWise was dependent upon participants being computer literate and having access to the internet. The majority of participants had been online for over five years $(86.3 \%)$ and used the internet for more than 10 hours a week (62.7\%). These rates of Internet engagement are considerably higher than reported elsewhere ( $68 \%$ and $21 \%$ respectively, (48)), highlighting the appeal of AsthmaWise to older adults who utilise the internet extensively. Obviously, this finding has ramifications for older adults that are not long-term confident users as well as for those that are not online at all. Recent Australian research suggests that while $85 \%$ of $55-59$ year olds use the internet, this rate falls to $50 \%$ of those aged 75 years and over (48). However, it is expected that levels of internet use seen in those aged 75 years and over 
will increase as the Baby Boomers age, reducing the need for alternate delivery channels. It is therefore suggested that practitioners providing online health education targeting older adults, in the near future, should consider using other delivery channels in conjunction with the Internet. This will increase the potential reach of the program whilst also ensuring that population segments are not excluded.

The majority of participants were female (66.7\%), which is higher than the proportion in NSW (50.7\%) (52). Most participants reported having two or more chronic diseases, with $59 \%$ reporting that their asthma co-occurred with arthritis; a proportion identical to other research findings (53). While the proportion of responders who did not speak English at home (17.6\%) was lower than the rate for NSW (26.5\%) (52), this is likely to have been due to AsthmaWise being provided solely in English. It is likely that AsthmaWise users were also highly e-health literate - that is skilled in the ability to find, understand and assess health information online (49). High e-health literacy is most common amongst younger, more educated people (50), like the AsthmaWise sample. Future iterations of AsthmaWise and other online self-management education programs should consider how to engage people from culturally and linguistically diverse backgrounds (CALD) as well as those with low ehealth literacy. The value of including a tool such as eHEALS (51) to measure participants' ehealth literacy should also be considered.

The discrepancy between the relatively large number of unique visitors and the lower number of registered participants may have been caused by casual visitors or due to 
problems with the registration process. While the researchers were contacted by participants during the pilot period, this was never in relation to registration difficulties suggesting that the difference was due to casual visitors. However, since visits were factored in to the data supplied by Google Analytics it is likely to have resulted in mean values significantly lower than those that would have been obtained if only data from the registered participants was examined. For instance, while the average visit length was reported as 8.31 minutes, which was considerable longer than that reported by the German Asthma Information Centre at 1.57 minutes (54), it is likely that registered users visited for longer periods of time. Although lessfewer people completed the post-test survey than the pre-test survey, such drop-out rates are not unusual with internet intervention trials (55). Further, follow-up of non-responders resulted in us acquiring data for just over two-thirds of participants who completed the original pre-test survey.

Results from the PHWSUQ indicated that while the usability of AsthmaWise had improved since usability testing, there was still scope for further improvement in terms of its overall usability. Our results indicate that exposure to AsthmaWise significantly improved participants' asthma knowledge, asthma control and asthma quality of life. While other interventions targeting asthma have also shown significant improvements in asthma control (20), reported changes to quality of life have varied from those showing improvements (56) to those finding minimal improvement (57). Although it has been argued that improved asthma knowledge is likely to lead to improved asthma management (58), these results should be interpreted with caution as a Cochrane review concluded that asthma education 
alone can improve perceived asthma symptoms but not health outcomes (59). The reduction in asthma self-management efficacy following exposure to AsthmaWise contradicts current knowledge which links high self-efficacy with better asthma control and asthma related quality of life $(60,61)$. It is possible that this drop in self-management efficacy occurred because, prior to exposure to AsthmaWise, participants were unaware of the seriousness of asthma.

The use of both online and offline recruitment methods is likely to have increased visibility of AsthmaWise, with a number of people who were not regular computer users contacting the researchers to ask if they could participate. While previous research has shown that people with asthma are willing to use both the internet and their phones to help them manage their asthma (62), the difficulty experienced in recruiting participants would suggest that older adults are not as open to the idea as younger persons. This reinforces the demographic profile of AsthmaWise users, as relatively young, long-term, confident internet users.

While non-responders were seen to not differ significantly from responders in terms of age, age at time of asthma diagnosis or asthma control, they were significantly more likely to perceive asthma as not being serious. This is consistent with previous research which has shown that adults aged over 65 years with a mix of co-morbidities, tend not to view asthma as serious (63). These results suggest that perceived seriousness of asthma may play a pivotal role in how users engage with a self-management program. 
The value of tailoring AsthmaWise to meet the needs of each individual user should be investigated. Such customisation would allow the program to provide dynamic, individualised care, which can adapt both to the users' disease experience and their environment thereby reinforcing findings both from the development of AsthmaWise and other studies $(64,65)$.

This study had strengths including the use of a repeated-measures design. Further, the use of standardised questions allowed the easy comparison of demographic data, while the scales for asthma knowledge, asthma control, asthma quality of life and the partners in health scale have established validity and reliability. However, our findings should be interpreted with caution due to: the relatively short period that AsthmaWise was available for viewing (just three months); possible sample bias due to self-selection, which resulted in a young, well educated, computer literate sample; and the lack of a control group. The evaluation relied on self-reported measures of physical change. It was not possible to calculate actual participation rates as we do not know how many eligible people saw the adverts for AsthmaWise and of those what percent met the eligibility criteria. Finally, the overlapping nature of respiratory diseases in older adults makes it possible that participants had a chronic disease with similar symptoms as asthma but had been misdiagnosed as having asthma $(3,66)$.

It is suggested that learnings-findings from this pilot study of AsthmaWise are-be incorporated into prospective versions of the intervention, and that in future the site 
remains live for a longer period of time. This would allow more participants to register and access AsthmaWise, which in turn would allow more complex analyses of the outcome variables. In particular, it would be possible to look at usage when users are segmented by asthma severity and/or medication use.

\section{Conclusions:}

This small pilot study indicates that an online asthma self-management education program can result in improved self-reported asthma knowledge, asthma control and asthma quality of life. Importantly, this occurred with a target group not normally considered to be technically literate. The need for asthma self-management education programs will continue to increase as the population ages and more older adults are living with asthma.

The results suggest that online programs could be successfully used to teach selfmanagement skills for other chronic diseases. Such programs could help to alleviated current GP time pressures. As recruiting participants proved harder than expected, it is suggested that future initiatives targeting this age group provide resources to support participants to accessing and utilising the appropriate technology. 


\section{References}

1. Australian Centre for Asthma Monitoring. Asthma in Australia 2008. Welfare Al of H and, editor. aihw.gov.au. Canberra: Australian Centre for Asthma Management; 2008 p. 1-215.

2. Australian Institute of Health and Welfare. Chronic diseases [Internet]. 2010 [cited 2012 Feb 24]. Available from: http://www.aihw.gov.au/chronic-diseases/

3. Goeman DP, Douglass JA. Optimal management of asthma in elderly patients: strategies to improve adherence to recommended interventions. Drugs and Aging. 2007;24(5):381-94.

4. Ho SF, Jones D. Morbidity in older people with self-reported asthma. Age \& Ageing. 1999;28(5):475-80.

5. Baptist AP, Deol BBK, Reddy RC, Nelson B, Clark NM. Age-specific factors influencing asthma management by older adults. Qualitative Health Research. 2010 Jan;20(1):117-24.

6. Bender BG, Bender SE. Patient-identified barriers to asthma treatment adherence: responses to interviews, focus groups, and questionnaires. Immunology and Allergy Clinics of North America. 2005;25(1):107-30.

7. Gibson PG, Ram FSF, Powell H. Asthma education. Respiratory Medicine. 2003;97(9):1036-44.

8. McGhan SL, Cicutto LC, Befus AD. Advances in development and evaluation of asthma education programs. Current Opinion in Pulmonary Medicine. 2005;11(1):61.

9. Department of Health and Ageing. Asthma. 2009.

10. National Asthma Council Australia. Asthma Management Handbook 2006. Foundations. Melbourne; 2006.

11. Cousens N, Goeman DP, Douglass J, Jenkins C. The needs of older people with asthma. Australian Family Physician. 2007;36(9):729.

12. Anhøj J, Nielsen L. Quantitative and qualitative usage data of an Internet-based asthma monitoring tool. Journal of Medical Internet Research. Journal of Medical Internet Research; 2004 Sep 3;6(3):e23.

13. Rasmussen LM, Phanareth $\mathrm{K}$, Nolte $\mathrm{H}$, Backer V. Internet-based monitoring of asthma: a long-term, randomized clinical study of 300 asthmatic subjects. Journal of Allergy \& Clinical Immunology. 2005;115(6):1137-42. 
14. Van der Meer V, Van Stel HF, Bakker MJ, Roldaan AC, Assendelft WJJ, Sterk PJ. Weekly self-monitoring and treatment adjustment benefit patients with partly controlled and uncontrolled asthma : an analysis of the SMASHING study. Respiratory Research. 2010;11(74):1-9.

15. Cruz-Correia R, Fonseca J, Lima L, Araujo L, Delgado L, Castel-Branco MG, et al. Webbased or paper-based self-management tools for asthma--patients' opinions and quality of data in a randomized crossover study. Studies in Health Technology \& Informatics. 2007;127:178-89.

16. Cruz-Correia R, Fonseca J, Lima L, Araujo L, Delgado L, Castel-Branco MG, et al. A comparison of web-based and paper-based self management tools for asthma. The Journal on Information Technology in Healthcare. 2007;5(6):357-71.

17. Finkelstein J, Cabrera MR, Hripcsak G. Internet-based home asthma telemonitoring: can patients handle the technology? Chest. 2000;117(1):148-55.

18. O'Hara C, Vethanayagam D, Majaesic C, Mayers I. Internet-based asthma education A novel approach to compliance: A case report. Can Respir J. 2006;13(1):30-2.

19. Glykas $\mathrm{M}$, Chytas $\mathrm{P}$. Web-based asthma collaboration managmeent and public awareness. The Journal on Information Technology in Healthcare. 2004;2(6):427-38.

20. Van der Meer V, Bakker MJ, Van den Hout WB, Rabe KF, Sterk PJ, Kievit J, et al. Internet-based self-management plus education compared with usual care in asthma: a randomized trial. Annals of Internal Medicine. American College of Physicians; 2009;151(2):110-20.

21. Alpay L, Toussaint PJ, Ezendam NPM, Rövekamp TAJM, Graafmans WC, Westendorp RGJ. Easing Internet access of health information for elderly users. Health Informatics Journal. SAGE Publications; 2004 Sep 1;10(3):185-94.

22. Cabana MD, Le TT. Challenges in asthma patient education. Journal of Allergy and Clinical Immunology. 2005;115(6):1225-7.

23. Ajzen I. The Theory of Planned Behavior. Organizational Behavior and Human Decision Processes. 1991;50:179-211.

24. Doshi A, Patrick K, Sallis J, Calfas K. Evaluation of physical activity web sites for use of behavior change theories. Annals of Behavioral Medicine. Springer New York; 2003;25(2):105-11.

25. Doshi A. The evaluation template for physical activity websites. Burns $P$, editor. 2011. p. 8. 
26. Webb TL, Joseph J, Yardley L, Michie S. Using the internet to promote health behavior change: a systematic review and meta-analysis of the impact of theoretical basis, use of behavior change techniques, and mode of delivery on efficacy. Journal of medical Internet research. Journal of Medical Internet Research; 2010 Jan 17;12(1):e4.

27. Hawkins RP, Kreuter M, Resnicow K, Fishbein M, Dijkstra A. Understanding tailoring in communicating about health. Health education research. 2008 Jun;23(3):454-66.

28. Fox MP. A systematic review of the literature reporting on studies that examined the impact of interactive, computer-based patient education programs. Patient Education and Counseling. 2009;77(1):6-13.

29. Cummins CO, Prochaska JO, Driskell M-M, Evers KE, Wright J a., Prochaska JM, et al. Development of Review Criteria to Evaluate Health Behavior Change Websites. Journal of Health Psychology. 2003 Jan 1;8(1):55-62.

30. Khaylis A, Yiaslas T, Bergstrom J, Gore-Felton C. A review of efficacious technologybased weight-loss interventions: five key components. Telemedicine journal and ehealth : the official journal of the American Telemedicine Association. Mary Ann Liebert, Inc., publishers; 2010 Nov;16(9):931-8.

31. Kerr C, Murray E, Stevenson F, Gore C, Nazareth I, Treweek S. Internet Interventions for Long-Term Conditions: Patient and Caregiver Quality Criteria. Journal of Medical Internet Research. 2006;8(3).

32. Brouwer W, Oenema A, Crutzen R, De Nooijer J, De Vries NK, Brug J. An Exploration of Factors Related to Dissemination of and Exposure to Internet-Delivered Behavior Change Interventions Aimed at Adults: A Delphi Study Approach. Journal of Medical Internet Research. 2008;10(2).

33. National Institute on Ageing and National Library of Medicine. Making your web site senior friendly: a checklist [Internet]. 2002. p. 15. Available from:

http://www.nlm.nih.gov/pubs/checklist.pdf

34. Nielsen J, Loranger H. Prioritizing web usability. Berkeley, CA, USA: New Riders; 2006.

35. Arch (W3C) A. Web accessibility for older users: a literature review [Internet]. W3C; 2008 [cited 2012 Feb 24]. Available from: http://www.w3.org/TR/wai-age-literature/

36. Xxxx, Yyyy, Zzzz (author details removed for peer review). Usability testing of XXXX with Older Adults. Computers Informatics Nursing.

37. Kritikos V, Krass I, Chan HS, Bosnic-Anticevich SZ. The validity and reliability of two asthma knowledge questionnaires. Journal of Asthma. 2005 Nov;42(9):795-801. 
38. British Thoracic Society, Scottish Intercollegiate Guidelines Network. British guidelines on the management of asthma. A national clinical guideline.

39. Thomas M, Gruffydd-Jones K, Stonham C, Ward S, Macfarlane T. Assessing asthma control in routine clinical practice: use of the Royal College of Physicians " 3 Questions". Primary Care Respiratory Journal. 2009;18(2):83-8.

40. Juniper EF, O'Byrne PM, Guyatt GH, Ferrie PJ, King DR. Development and validation of a questionnaire to measure asthma control. European Respiratory Journal. 1999;14(4):902-7.

41. QualityMetric. Asthma Control Test (ACT) [Internet]. [cited 2012 Dec 14]. Available from:

http://www.qualitymetric.com/WhatWeDo/DiseasespecificHealthSurveys/AsthmaCo ntrolTestACT/tabid/190/Default.aspx

42. Marks GB, Dunn SM, Woolcock AJ. A scale for the measurement of quality of life in adults with asthma. Journal of Clinical Epidemiology. 1992 May;45(5):461-72.

43. Marks GB, Dunn SM, Woolcock AJ. An Evaluation of an Asthma Quality of Life Questionnaire as a Measure of Change. Journal of Clinical Epidemiology. 1993;46(10):1103-11.

44. Battersby MW, Ask A, Reece MM, Markwick M, Colllns P. The Partners in Health scale: The development and psychometric properties of a generic assessment scale for chronic condition self-management. Australian Journal of Primary Health. 2003;9(2 \& 3):41-52.

45. Nahm E-S, Resnick B, Mills ME. Development and pilot-testing of the perceived health web site usability questionnaire (PHWSUQ) for older adults. In: Park HA, Murray P, Delaney $C$, editors. Consumer-Centred Computer-Supported Care for Healthy People: Proceedings of NI2006. Lansdale, PA, USA: IOS Press; 2006. p. 38-44.

46. Chew L, Griffin JM, Partin MR, Noorbaloochi S, Grill JP, Snyder A, et al. Validation of screening questions for limited health literacy in a large VA outpatient population. Journal of General Internal Medicine. Springer New York; 2008 May;23(5):561-6.

47. Xxx, Yyy, Zzz, Aaa (author details removed for peer review). Internet SelfManagement Reporting Uniform Framework (iSMURF): the need for uniform reporting criteria when reporting internet interventions. Computers, Informatics, Nursing. 2013; Under revi.

48. Burns P, Jones SC, Iverson D, Caputi P. Riding the wave or paddling in the shallows? Understanding older Australians' use of the internet. Health Promotion Journal of Australia. 2012;23(2):145-8. 
49. Norman CD, Skinner HA. eHealth Literacy: Essential Skills for Consumer Health in a Networked World. Journal of medical Internet research. 2006 Jan;8(2):e9.

50. Neter E, Brainin E. eHealth literacy: extending the digital divide to the realm of health information. Journal of medical Internet research. 2012 Jan;14(1):e19.

51. Norman CD, Skinner HA. eHEALS: The eHealth Literacy Scale. Journal of medical Internet research. 2006 Jan;8(4):e27.

52. Australian Bureau of Statistics. New South Wales: All people - usual residence [Internet]. 2011 Census QuickStats. 2012 [cited 2012 Dec 28]. Available from: http://www.censusdata.abs.gov.au/census_services/getproduct/census/2011/quickst at/1

53. Caughey GE, Vitry Al, Gilbert AL, Roughead EE, Vitry Al, Gilbert AL, et al. Prevalence of comorbidity of chronic diseases in Australia. BioMed Central Public Health.

2008;8:221.

54. Wjst M. When Air Is Rare: Behind the Scenes of an Asthma Web Site. Journal of Asthma. 2001;38(5):399-404.

55. Burns P, Jones S, Iverson D, Caputi P. Internet Self-Management Reporting Uniform Framework: the need for uniform reporting criteria when reporting Internet interventions. Unpublished Manuscript, Centre for Health Initiatives, University of Wollongong. 2012;

56. Atherton M. Outcome measures of efficacy associated with a web- enabled asthma self-management programme. 2000.

57. Van der Meer V, Van Stel HF, Detmar SB. Internet-based self-management offers an opportunity to achieve better asthma control in adolescents. Cardiopulmonary Physical Therapy Journal. 2007;18(4):19(1).

58. Bauman A, Craig A, Dunsmore J, Browne G, Allen D, Vandenberg R. Removing barriers to effective self-managemet of asthma. Patient Education and Counseling. 1989;14:217-26.

59. Gibson PG, Powell H, Wilson A, Hensley MJ, Abramson MJ, Bauman A, et al. Limited (information only) patient education programs for asults with asthma. Cochrane Database of Systematic Reviews. 2002;(1).

60. Lavoie KL, Bouchard A, Joseph M, Campbell TS, Favreau H, Bacon SL. Association of asthma self-efficacy to asthma control and quality of life. Annals of behavioral medicine : a publication of the Society of Behavioral Medicine. 2008 Aug;36(1):100-6. 
61. Mancuso CA, Rincon M, McCulloch CE, Charlson ME. Self-efficacy, depressive symptoms, and patients' expectations predict outcomes in asthma. Medical Care. 2001;39(12):1326-38.

62. Fonseca JA, Costa-Pereira A, Delgado L, Fernandes L, Castel-Branco MG. Asthma patients are willing to use mobile and web technologies to support self-management. Allergy. 2006;61(3):389-90.

63. Andrews KL, Jones SC. "We would have got it by now if we were going to get it..." An analysis of asthma awareness and beliefs in older adults. Health Promotion Journal of Australia. 2009;20(2):146-50.

64. Sanders DL, Aronsky D. Biomedical Informatics Applications for Asthma Care: A Systematic Review. J Am Med Inform Assoc. 2006;13(4):418-27.

65. Andrews KL, Jones SC, Mullan J. Perceptions and practices of adults with asthma: a social cognitive analysis. Journal of Asthma and Allergy Educators. $2012 \mathrm{Sep}$ 28;(Publishe online: 28 September):1-8.

66. King MJ, Hanania NA. Asthma in the elderly: current knowledge and future directions. Current Opinion in Pulmonary Medicine. 2010;16(1):55-9. 
Table 1: The Internet Self-Management Uniform Reporting Framework (iSMURF)

\begin{tabular}{|c|c|}
\hline \multicolumn{2}{|l|}{ Website design } \\
\hline Technological platform & Moodle \\
\hline Use of evidence based guidelines in site design & Yes \\
\hline Utilisation of Web 2.0 technology & No \\
\hline \multicolumn{2}{|l|}{ Support } \\
\hline $\begin{array}{l}\text { Provision of computer/technical equipment to } \\
\text { participants }\end{array}$ & No \\
\hline Provision of technical support & No \\
\hline Use of clinicians/moderators & No \\
\hline Frequency of contact & N/A \\
\hline Mode of contact & $\mathrm{N} / \mathrm{A}$ \\
\hline Provision of peer support e.g. forums & No \\
\hline Was intervention incorporated into usual care & No \\
\hline \multicolumn{2}{|l|}{ Study design } \\
\hline Date of study & February - April 2012 \\
\hline Length of study & 3 months \\
\hline \multirow[t]{2}{*}{ Recruitment methods } & Unpaid \\
\hline & Online \& offline \\
\hline Potential reach of intervention & $\begin{array}{l}\text { Open to adults aged } 55 \text { years and over with a } \\
\text { diagnosis of asthma }\end{array}$ \\
\hline \multirow[t]{2}{*}{ Use of incentives } & $\begin{array}{l}\text { A draw to win a } 32 \text { " LED TV was open to participants } \\
\text { who registered early }\end{array}$ \\
\hline & $\begin{array}{l}\text { A draw to win one of } 3 \times \$ 100 \text { gift vouchers - open to } \\
\text { those who completed both pre and post-test. }\end{array}$ \\
\hline Use of reminders & Yes -1 email \\
\hline \multicolumn{2}{|l|}{ Website use } \\
\hline \multirow[t]{3}{*}{ Engagement } & Total number of visits \\
\hline & Average number of visits by participants \\
\hline & Most viewed page \\
\hline \multirow[t]{2}{*}{ Exposure } & Total duration of viewing \\
\hline & Average viewing time by participants \\
\hline Attrition & $\begin{array}{l}\text { Over time e.g. baseline and post intervention as } \\
\text { minimum }\end{array}$ \\
\hline \multicolumn{2}{|l|}{ User characteristics } \\
\hline \multirow[t]{2}{*}{ Age } & Mean $=62.5$ yrs $(n=51, S D=6.73)$ \\
\hline & Range $50-85$ yrs \\
\hline Sex & Female $=66.7 \%(n=34)$ \\
\hline Ethnicity & English as a second language $=17.6 \%(n=9)$ \\
\hline Computer confidence/internet experience & Quite comfortable or very comfortable $=94.1 \%(n=49)$ \\
\hline \multirow[t]{4}{*}{ Level of education } & Completed primary school $=5.9 \%(n=3)$ \\
\hline & Some secondary school = $15.7 \%(n=8)$ \\
\hline & Completed secondary school $=70.6 \%(n=36)$ \\
\hline & Completed tertiary studies $=7.8 \%(n=4)$ \\
\hline Health literacy & Limited $/$ marginal $=17.6 \%(n=9)$ \\
\hline Number of co-morbid conditions & $2+$ chronic diseases $=82.4 \%(n=42)$ \\
\hline \multicolumn{2}{|l|}{ Reporting Outcomes } \\
\hline Inclusion of costs/ cost effectiveness data & No \\
\hline Participant satisfaction & Qualitative/quantitative \\
\hline
\end{tabular}


Table 2: Perceived Health Web Site Usability Questionnaire - Total and Subscale Mean Scores

\begin{tabular}{|c|c|c|c|c|c|c|c|c|c|}
\hline \multirow[b]{2}{*}{ Dimension } & \multicolumn{3}{|c|}{ Usability Testing } & \multicolumn{2}{|c|}{ Intervention } & \multirow[b]{2}{*}{$\mathbf{t}$} & \multirow[b]{2}{*}{$\mathbf{p}$} & \multirow[b]{2}{*}{ df } & \multirow[b]{2}{*}{$\mathbf{r}$} \\
\hline & $\begin{array}{l}\text { Score } \\
\text { range }\end{array}$ & $\begin{array}{r}\text { Mean } \\
(S D)\end{array}$ & $\begin{array}{r}\text { Mean } \\
\text { converted* }\end{array}$ & $\begin{array}{r}\text { Mean } \\
(S D)\end{array}$ & $\begin{array}{l}\text { Mean } \\
\text { converted* }\end{array}$ & & & & \\
\hline Satisfaction & $(4-28)$ & $\begin{array}{r}19.40 \pm \\
5.44\end{array}$ & $69.30 \%$ & $\begin{array}{r}22.60 \pm \\
4.39\end{array}$ & $80.71 \%$ & 2.22 & .030 & 61 & .27 \\
\hline Ease of use & $(3-21)$ & $\begin{array}{r}13.92 \pm \\
1.68\end{array}$ & $66.30 \%$ & $\begin{array}{r}16.42 \pm \\
3.23\end{array}$ & $78.20 \%$ & .54 & .591 & 61 & .07 \\
\hline Usefulness & $(3-21)$ & $\begin{array}{r}12.77 \pm \\
1.91\end{array}$ & $61.00 \%$ & $\begin{array}{r}15.40 \pm \\
4.34\end{array}$ & $73.33 \%$ & 1.92 & .059 & 61 & .24 \\
\hline Total & $(10-70)$ & $\begin{array}{r}46.07 \pm \\
1.40\end{array}$ & $65.71 \%$ & $\begin{array}{r}52.30 \pm \\
2.71\end{array}$ & $74.71 \%$ & 2.02 & .048 & 61 & .25 \\
\hline
\end{tabular}

* Mean value/highest possible score $\times 100=$ total percent 
Table 3: Paired t-test results showing changes in asthma knowledge, asthma control, asthma quality of life and asthma self management efficacy

\begin{tabular}{|c|c|c|c|c|c|c|c|c|}
\hline & \multicolumn{2}{|c|}{ Pre-test } & \multicolumn{2}{|c|}{ Post-test } & \multirow[b]{2}{*}{ df } & \multirow[b]{2}{*}{$\mathbf{t}$} & \multirow[b]{2}{*}{ p } & \multirow[b]{2}{*}{$\mathbf{r}$} \\
\hline & Mean & SE & Mean & SE & & & & \\
\hline Asthma Knowledge & 3.50 & .12 & 5.13 & .13 & 44 & -11.82 & .000 & .87 \\
\hline Asthma Control & 2.16 & .15 & 1.34 & .16 & 49 & 4.95 & .000 & .58 \\
\hline AQoL & 3.20 & .34 & 2.54 & .29 & 49 & 2.61 & .012 & .35 \\
\hline AQoL Breathlessness & 8.06 & .78 & 6.38 & .70 & 49 & 2.20 & .032 & .30 \\
\hline AQoL Mood & 7.70 & .68 & 6.02 & .65 & 49 & 2.53 & .015 & .34 \\
\hline AQoL Social & 6.18 & 1.07 & 4.64 & .82 & 49 & 2.64 & .011 & .35 \\
\hline AQoL Concerns & 7.52 & 1.03 & 6.18 & .82 & 49 & 1.98 & .053 & .27 \\
\hline Asthma self management efficacy & 19.36 & 2.44 & 28.20 & 2.25 & 49 & -4.06 & .000 & .50 \\
\hline
\end{tabular}

A higher mean score indicates an improvement in asthma knowledge, whereas lower mean values indicate improved asthma control, asthma quality of life and self-management efficacy. 